\title{
Simulating and analysing climate change impacts on crop yields in Morocco using the CARAIB dynamic vegetation model driven by Med- CORDEX projections
}

\author{
Iliass Loudiyi ${ }^{1}$, Ingrid Jackemin ${ }^{2}$, Bernard Tychon ${ }^{2}$, Louis Francois ${ }^{2}$, Mouanis Lahlou ${ }^{3}$, Joost \\ Wellens ${ }^{2}$, and Riad Balaghi ${ }^{4}$ \\ ${ }^{1}$ Institute of Astrophysics and Geophysics, University of Liège, Belgium (i.loudiyi@doct.uliege.be) \\ ${ }^{2}$ Research Unit : SPHERES, University of Liège, Belgium \\ ${ }^{3}$ The Agronomic and Veterinary Institute Hassan 2, Morocco \\ ${ }^{4}$ National Institute of Agronomic Research, Morocco
}

Morocco, by its geographical position and its climate, is strongly affected by climate change and presents an ever-increasing vulnerability. In fact, the country's economy, being very dependent on agriculture, would be greatly affected. It is therefore necessary to further develop knowledge about climate change and strengthen forcasting systems for predicting the impacts of climate change.

The agriculture in Morocco is largely dominated by rainfed crops and therefore dependent on pluviometry. According to the Global Yield Gap Atlas, about $43 \%$ of arable land is devoted to cereals, $7 \%$ to plantation crops (olives, almonds, citrus, grapes, dates), $3 \%$ to pulses, $2 \%$ to forage, $2 \%$ to vegetables, $2 \%$ to industrial crops (sugar beets, sugar cane, cotton) and oilseeds, and $42 \%$ is fallow. In this project we are going to focus on cereals, olives, potatoes and sugar beets. Regarding the climate, Morocco is characterized by a wide variety of topographies ranging from mountains to plains, oasis and Saharan dunes. For this reason, the country experiences diverse climatic conditions with large spatial and intra- and inter-annual variability of precipitation. Morocco faces irregular rain patterns, cold spells and heat waves increasingly resulting in droughts, which significantly affects agriculture.

Our research, funded by a bilateral project of Wallonie-Bruxelles International, aims to study the response of Moroccan agriculture to climate change, using the dynamic vegetation model CARAIB (CARbon Assimilation In the Biosphere) developed within the Unit for Modelling of Climate and Biogeochemical Cycles (UMCCB) of the University of Liège. This spatial model includes crops and natural vegetation and may react dynamically to land use changes. Originally constructed to study vegetation dynamics and carbon cycle, it includes coupled hydrological, biogeochemical, biogeographical and fire modules. These modules respectively describe the exchange of water between the atmosphere, the soil and the vegetation, the photosynthetic production and the evolution of carbon stocks and fluxes in this vegetation-soil system. The biogeographical module describes, for natural vegetation, the establishment, growth, competition, mortality, and regeneration of plant species, as well as the occurrence and propagation of fires. For crops, a 
specific module describes basic management (sowing, harvest, rotation) and phenological phases.

Model simulations are performed across north-west Morocco, where the crops activities are important, by using different input data. The timeline of simulations is divided in two periods: past (from 1901 to 2018[LF1] ) and future (from 2019 to 2100). For the past period, we are using high resolution (30 arc sec) gridded climate data derived from WorldClim (climatology) and interpolated anomalies from Climate Research Unit CRU (trend and variability). For the future period, we use interpolated and bias-corrected fields from a regional climate model (ALADIN-Climate) from the Med-CORDEX initiative run at a spatial resolution of $12 \mathrm{~km}$ and for three different Representative Concentration Pathway scenarios (RCP2.6, RCP4.5 and RCP8.5). 